\title{
Atık Gazete Kağıdından Yalıtım Malzemesi Üretimi
}

\author{
Hanifi BİNICI ${ }^{* 1}$, Ahmet H.SEVINÇ ${ }^{1}$, Velit EFE ${ }^{1}$ \\ ${ }^{1}$ Kahramanmaraş Sütçü İmam Üniversitesi, İnşaat Mühendisliği Bölümü, Kahramanmaraş \\ Geliş tarihi: 02.07.2015 Kabul tarihi:30.11.2015
}

\section{Özet}

Bu çalışmanın amacı atık gazete kâăıdı, vermikülit, perlit, çinko boraks ve alçı ile yalıtım malzemesi üretmektir. $\mathrm{Bu}$ amaçla atık gazete kâğıdı hamur haline gelene kadar bir gün suda bekletildikten sonra değişik oranlarda vermikülit, perlit ve çinko boraks katılmıştır. Numunelerin üretiminde bağlayıcı olarak

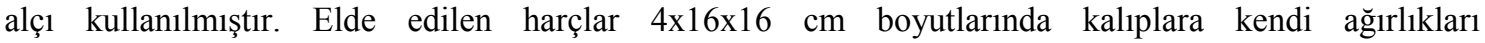
yerleştirilmiştir. Bazı numenlerin üretiminde $5 \mathrm{~mm}$ çapında kamış tek ve çift sıra ızgara şeklinde yerleştirilmiştir. Numuneler 24 saat $100^{\circ} \mathrm{C}$ 'de etüvde bekletilmiş̧ir. Ayrıca numunelerin yangın direncini artırmak için örneklerin karışımında belirli oranlarda vermikülit ve çinko boraks kullanılmıştır. Numunelerin birim hacim ağırlıkları, su emme oranları, 1sı iletim ve ultra ses geçirgenlik katsayısı ile eğilme ve basınç dayanımları belirlenmiştir. Çift sıra kamış kullanılarak üretilen numunelerin ısı iletim ve ultra ses geçirgenlik katsayıları düşük bulunmuştur. Elde edilen sonuçlar bu malzemelerin 1sı yalıtımı amacıyla kullanılabileceğini göstermiştir. Ayrıca önerilen karışımların yangına dirençlerinin ASTM standardına uygun olduğu belirlenmiştir.

Anahtar kelimeler: Atık gazete kağıdı, Vermikülit, Perlit, Çinko boraks, Yalıtım

\section{The Production of Insulation Materials Made with Waste Newsprint}

\begin{abstract}
The aim of this study is to produce insulation materials made with waste newsprint, vermiculite, perlite, zinc borax to and plaster. For this purpose waste newsprints until it becomes dough for one day in water at different rates vermiculite, perlite and zinc borax participated. The resulting slurry was placed in the mold by its own weight as $4 \times 16 \times 16 \mathrm{~cm}$ to $5 \mathrm{~mm}$ diameter cane monolayer and double row grid and pressure is applied. Plaster is used as binder in the production of the samples. The obtained mortars was placed in the mold in $4 \times 16 \times 16 \mathrm{~cm}$ their own weight. Some of those in the production of cane number 5 $\mathrm{mm}$ in diameter were placed in single and double rows of the grid. The samples were stored in an oven at $100{ }^{\circ} \mathrm{C}$ for 24 hours. In addition, to increase the fire resistance of the sample certain ratio vermiculite and zinc borax was used.
\end{abstract}

\footnotetext{
* Yazışmaların yapılacağı yazar: Hanifi BİNíCI, Kahramanmaraş Sütçü İmam Üniversitesi, İnşaat Mühendisliği Bölümü, Kahramanmaraş, hbinici@ksu.edu.tr
} 
Unit weigh, water absorption ratio, thermal insulation and ultra sound transmission coefficient, flexural and compressive strengths of samples were determined. The samples were produced using a double row of cane thermal insulation and ultra-sound permeability coefficients were low. These results indicate that those materials can be used for thermal insulation purpose. Furthermore, the mix proposed satisfies the fire resistant requirements of ASTM Standards.

Keywords: Waste newsprint, Vermiculite, Perlite, Zinc borax, Insulation

\section{GİRIŞ}

Türkiye'de kışın ısınma maliyetleri, yazın ise soğutma masrafları çok fazla olduğundan bu maliyetleri azaltmak için binalara yalıtım yapılmaktadır. Türkiye'de harcanan enerjinin yaklaşık \%40'1 konutlarda tüketilmektedir. Bunun \%80'i de ısınma amaçlıdır. Bu nedenle ülkemizde mevcut binalarda çeşitli yalıtım malzemeleri kullanılmaktadır [1].

Doğal kaynaklar dünya nüfusunun artması nedeni ile git gide azalmaktadır. $\mathrm{Bu}$ yüzden doğal kaynaklar, geri dönüşüm ile korunabilir. Ayrıca malzeme tüketimi azaltılabilir ve nitelikli atıklar geri dönüştürülerek doğal kaynaklar verimli kullanılabilir. Dolayısıyla geri dönüşüm doğal kaynaklarımızın korunması ve verimli kullanılması için çok önemlidir [2]. Son yıllarda birçok atık malzeme inşaat mühendisliğinde değişik amaçlarla kullanılması yaygınlaşmaktadır [3-10].

Enerji tasarrufu, ekonomik ve stratejik nedenlerle günümüzde çok önem kazanmıştır. Toplam tüketilen enerjinin $\mathrm{AB}$ 'de $\% 40$ '1 binalarda tüketilmektedir, bunun da yaklaşık yarısı duvarlardan geçen 1sı yoluyla gerçekleşmektedir [11]. Son yıllarda bina yapımında kullanılmaya başlanan ve yaygınlaşan, yeni yapı malzemeleri ve yapım sistemlerinin yapı fiziği ve konforu açısından birçok yarar sağlamıştır. Bu çerçevede bina duvarlarının yalıtılması, enerji tasarrufu imkânı sağlaması nedeniyle, yeni araştırmalara açık bir konudur [12-14].

Türkiye'de selüloz kaynakları sınırlıdır. Selüloz üretimi bir fabrika dışında yapılmadığından ithal edilmektedir. Selüloz üretimi başlı başına büyük bir organizasyondur. Fabrikanın kullanabileceği orman alanları, kütüklerin fabrikaya nakli ve işlenmesi yoğun çabalar ve büyük yatırımlar gerektirir. Kullanılmış kâğıdın ham madde olarak kullanılması fabrika alanını küçültmektedir. Selülozda olduğu gibi bu fabrikalar da ham madde kaynaklarına yakın olmak isterler. $\mathrm{Bu}$ nedenle büyük şehirlerin kenarını tercih ederler. $\mathrm{Bu}$ şehirlerde ortaya çıkan kullanılmış kâğıt bireysel toplayıcılarda çok geniş ve karmaşık bir yapıdadır. Günümüzde teknolojinin her geçen gün gelişmesiyle azalacağ 1 düşünülen kâğıt tüketimi, bunun tam tersine teknolojinin gelişmesiyle artmıştır. Dünyada kâğıt tüketimine olan gereksinimin artması, buna karşın kâğıt üretiminde kullanılan selülozun hammaddesi olan odun, saman, pamuk gibi doğal kaynakların azalması, orman yetiştirmenin uzun süre alması, çevre kirliliği ve enerji maliyetlerinin artması, kâğıt üreticilerinin kullanılmış kâğıt kaynağına yönelmesini zorunlu kılmıştır [15, 16]. Sıcak demircilik işlemlerden sonra, gün sonunda dükkânlarından atık şekilde ortaya çıkan demir tozları toplanıp atılmaktadır. Yapılan bu çalışma ile demir tozu atıkların harca katılmasıyla daha az girdi kullanıldığı için ekonomik beton elde edilecektir. Ayrıca bu durum çevrenin korunmasına katkı sağlayacaktır. Önceki çalışmalardan da anlaşılacağı üzere artık dünyamızda atıkların değerlendirilmesi büyük önem arz etmektedir. Bu bağlamada çalışmanın amacı, atıkların değerlendirilerek uygun yalıtım malzemesi üretmektir. Çalışma ile çok daha düşük 1sı iletim katsayısına sahip, yangına dirençli olan bir yalıtım malzemesinin üretimi amaçlanmaktadır. $\mathrm{Bu}$ sayede hem bölge insanları atıklardan yaralanacak, hem seri üretim ile istihdam yaratılacak hem de milli ekonomiye katk1 sağlanacaktır.

Doğal kaynakların hızla tükenmesi nedeniyle alternatif kaynaklara özellikle doğal atıklarının kullanılması ön plana çıkmaktadır. Isı yalıtımı 
konusunda yapılan çalışmaların kısıtlı olması sebebiyle yaptığımız çalışmalar ile literatüre katkı sağlanacaktır. Diğer yandan son yıllarda enerjinin daha pahalı hale gelmesi, yeni 1s1 yalıtım malzemelerinin geliştirilmesi konusundaki çalışmalar hız kazanmıştır. Üretilen numunelerin birim hacim ağırlığı, su emme, eğilme ve basınç dayanımları belirlenmiştir. Ayrıca, 1sı iletim katsayısı, ultra ses geçirgenlik katsayısı ve yangın dirençleri araştırılmıştır.

\section{MATERYAL VE METOT}

\subsection{Materyal}

\subsubsection{Atık Gazete Kâğıdı}

Herhangi bir kullanım alanında fonksiyonunu tamamlayan ve atılan her türlü kâğıt, karton ve mukavvalara atık kâğıt denilmektedir. Türkiye'de kâğıt tüketiminin artmasına paralel olarak, evsel ve endüstriyel katı atıklarla birlikte atılan kâğıt miktarları artmakta ve kâğıdın hammaddesi olan orman varlıkları ciddi olarak tehdit altına girmektedir.

\subsubsection{Vermikülit}

Mikanın doğal aşınmasıyla oluşan vermikülit bir silikat mineralidir. Yüksek sıcaklıklarda genleşebilme özelliğiyle çok hafif ve yanmaz bir malzemedir. $\mathrm{Bu}$ çalışmada tercih edilmesinin nedeni yalıtım özelliğinin yüksek olmasıdır.

\subsubsection{Perlit}

Özellikle inşaat sektörü alanında önemli bir işleve sahip olan perlit, yapı malzemesi olarak kullanılan bir maddedir. İçeriğinde $\% 74 \quad \mathrm{SiO}_{2}$ ve $\% 15 \mathrm{Al}_{2} \mathrm{O}_{3}$ bulunur. Volkanik karakterli bir maddedir. Çok hafif olması en önemli özelliğidir. Yap1 malzemesi olarak kendine alternatif olan madde ve karışımlara oranla \%50 oranında daha hafiftir.

\subsubsection{Alçı}

Çalışmada toz şeklinde susuz alçı kullanılmıştır.

\subsection{5. Çinko Boraks}

Türkiye sahip olduğu bor rezervleri ve cevherlerinin kalitesi ile dünyanın önde gelen ülkelerindendir. Dolayısı ile değişik bor ürünleri elde edilmesine yönelik çalışmaların yapılmasına ihtiyaç duyulmaktadır. Dünyada ticari olarak üretilen 175 civarında özel bor kimyasalı mevcut olup, çinko borat bunlardan bir tanesidir [17]. Türkiye dünya bor rezervlerinin $\% 72$ 'sine sahiptir. Kütahya ilinin Emet ilçesi ile Balıkesir ilinin Bigadiç ilçesi dünyanın en geniş kolemanit yataklarına sahiptir [18]. Çalışmada çinko boraks $\left(\mathrm{ZnO} . \mathrm{B}_{2} \mathrm{O}_{3}\right)$ alev geciktirici ve duman bastırıcı olarak kullanılmıştır.

\subsection{Metot}

\subsubsection{Numunelerin Hazırlanması}

\subsubsection{Lifli Kompozitler (L)}

$\mathrm{Bu}$ amaçla atık kâğıt su içerisinde 24 saat bekletildikten sonra elde edilen hamura Çizelge 1'de verilen oranlarda, bağlayıcı olarak alçı, perlit, ve vermikülit ya da çinko boraks karıştırılmıştır. Elde edilen homojen karışımdan $4 \times 16 \times 16 \mathrm{~cm}$ boyutlarında numuneler üretilmiştir. Numuneler yaklaşık 24 saat $100^{\circ} \mathrm{C}$ 'de etüvde bekletilmiştir.

Çizelge 1. Kompozitlerin karışım oranları (\%, ağırlıkça)

\begin{tabular}{|c|c|c|c|c|c|}
\hline $\begin{array}{c}\text { Örnek } \\
\text { no }\end{array}$ & $\begin{array}{c}\text { Gazete } \\
\text { kâğıdı }\end{array}$ & Perlit & Alçı & $\begin{array}{c}\text { Çinko } \\
\text { boraks }\end{array}$ & Vermikülit \\
\hline A1L & 80 & 10 & 10 & - & - \\
\hline A2L & 70 & 20 & 10 & - & - \\
\hline A3L & 75 & 10 & 10 & 5 & - \\
\hline A4L & 65 & 20 & 10 & 5 & - \\
\hline A5L & 75 & 10 & 10 & - & 5 \\
\hline A6L & 65 & 20 & 10 & - & 5 \\
\hline
\end{tabular}

\subsubsection{Tek Sıralı Izgaralı Kompozitler (TI)}

Çizelge 1'deki oranlar kullanılarak aynı boyutta ancak çapı $3 \mathrm{~mm}$ olan kamışlar (Şekil 2) tek 
tabaka halinde kullanılarak 1zgaralı kompozitler üretilmiştir. Numunelerin kamışlarla 1zgara şeklindeki kesite Şekil 1'de ve üretilen numuneler ise Şekil 2'de verilmiştir.
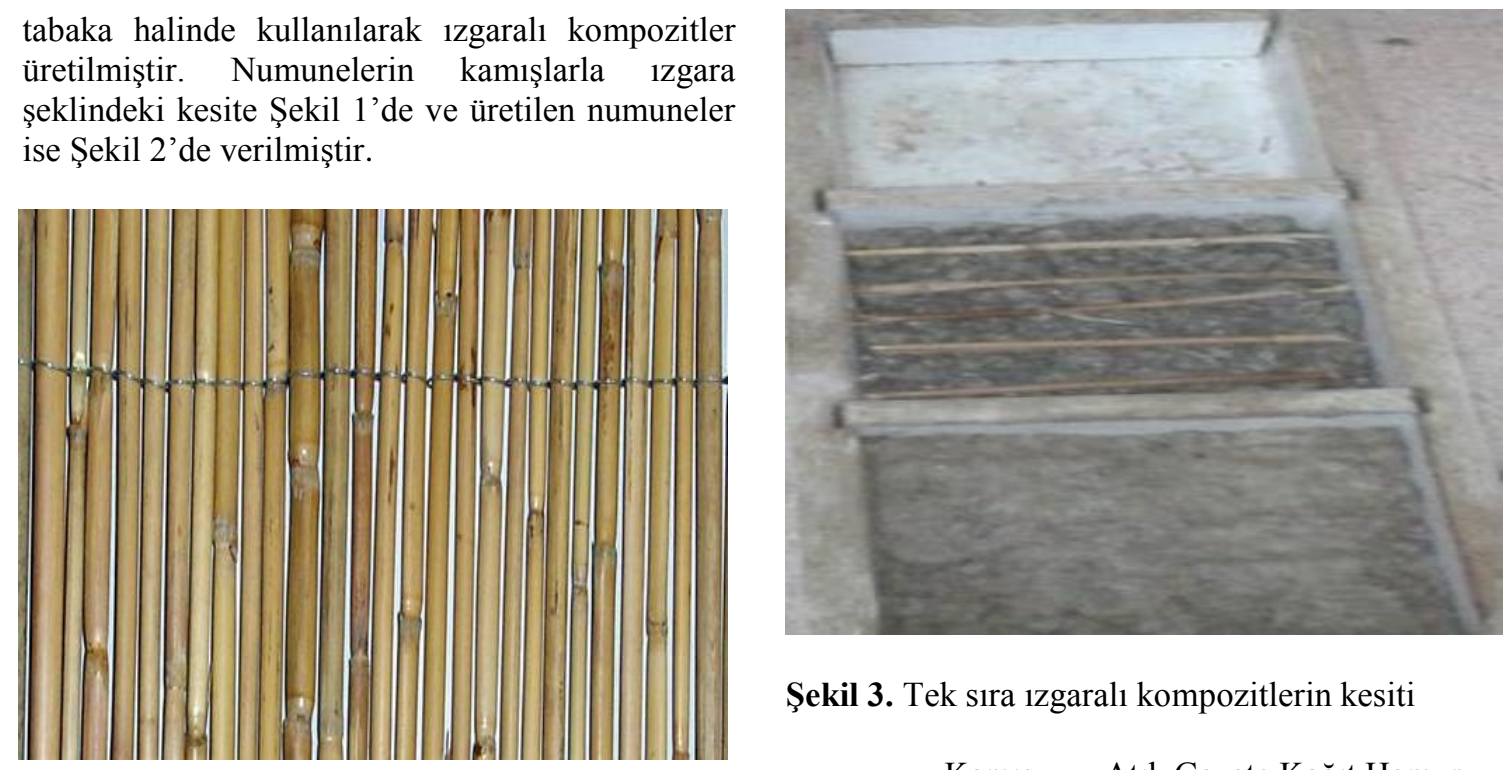

Şekil 3. Tek sıra ızgaralı kompozitlerin kesiti

Şekil 1. Tek ve çift sıra izgaralı kompozitlerde kullanılan kumaşlar

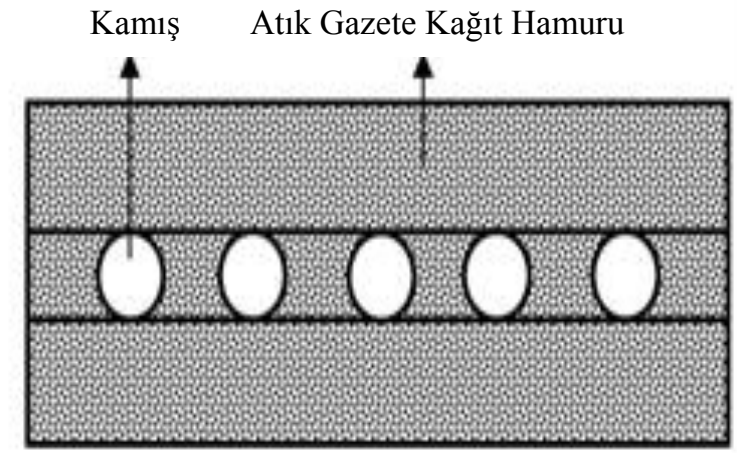

Şekil 2. Tek sıra kamışların numune içerisindeki yerleştirilmesi ve kesiti

\subsubsection{3. Çift Sıralı Izgaralı Kompozitler (ÇI)}

Çizelge 1'deki oranlar kullanılarak aynı boyutta ancak çapı $3 \mathrm{~mm}$ olan kamışlar iki tabaka halinde kullanılarak izgaralı kompozitler üretilmiştir. Şekil 4'de numunelerin kamışlarla çift tabakalı ızgara şeklindeki görünüşleri ve Şekil 5'de ise üretilen numuneler verilmiştir. Yeterince kuruyan numuneler etüvde $105^{\circ} \mathrm{C}^{\prime} \mathrm{de} 20 \mathrm{dk}$ kurutulduktan sonra test yapmaya hazır ha le getirilmiştir.

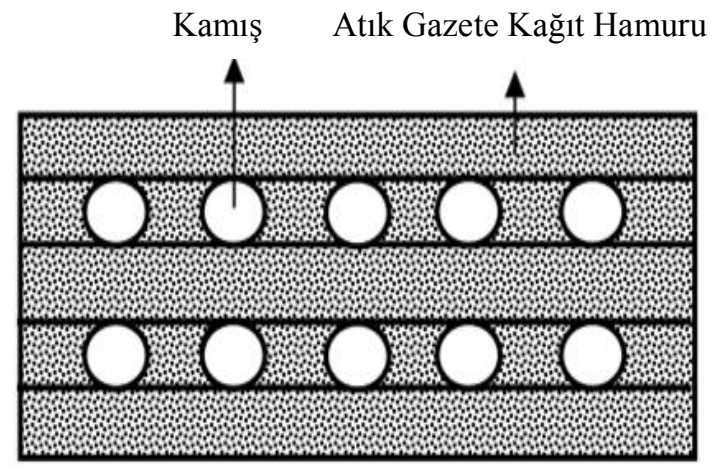

Şekil 4. Çift sıra kamışların yerleştirilmesi ve kesiti

\subsubsection{Birim Hacim Ağırlık ve Su Emme Değerleri}

Üretilen örneklerin birim hacim ağırlıkları ve su emme değerleri bulunmuştur. Yalıtım malzemelerinin birim hacim ağırlıkları TS EN 2823'e göre, su emme değerleri ASTM C 67-03'e göre [18] yapılmıştır.

\subsubsection{Ultra Ses Geçiş Hızı}

Ultrasonik test cihazının kullanılmasıyla, malzeme içerisine gönderilen ses dalgalarının malzemenin bir yüzeyinden diğerine geçme süresi ölçülmekte, dalga hızı hesaplanmaktadır. Hesaplanan ses üstü 
dalga hızı ile malzemenin basınç dayanımı ve diğer özellikleri arasındaki ilişki yaklaşık olarak elde edilebilmektedir [19]. Numunenin bir yüzeyinden içeriye gönderilen ses üstü dalganın, bloğun diğer bir yüzeye ne kadar zamanda geçtiği ölçüldükten sonra, dalga hızı aşağıdaki gibi hesaplanmaktadir:

$\mathrm{V}=(\mathrm{S} / \mathrm{t}) \cdot 10^{6}$

Burada; V = Dalga hızı $(\mathrm{km} / \mathrm{s}), \mathrm{S}=$ Proplar arası mesafe (Malzeme bloğunun ses üstü dalga gönderilen yüzeyi ile dalganın alındığı yüzeyi arasındaki mesafe, $(\mathrm{km}), \mathrm{t}=$ Dalganın gönderilmiş olduğu malzeme yüzeyinden, alındığı yüzeye kadar geçen zamandır (s) [20]. Bu deneyde numunelerin karşılıklı olarak pürüzsüz yüzeyleri belirlenmiş ve pandit cihazının iki başlığ $\breve{g}_{1}$ gres yağ ile yağlanmıştır. Yağlanan bu iki başlık numunenin yüzeyine karşılıklı gelecek şekilde sabitlenmiş ve sonra pandit cihazının okumaları yapılmıştır. $\mathrm{Bu}$ okumaların en küçük olanı alınmış ve yukarda verilen formül ile ultra ses hızı belirlenmiştir.

\subsubsection{Isı İletim Katsayısı}

Is1 iletim katsayıs1 ASTM C 1113- 90'de verilen [21] Hot Wire Metodu ile bulunmuştur.

\subsubsection{Basınç ve Eğilme Dayanımı}

$16 \times 16 \times 4 \mathrm{~cm}$ boyutlu numunelerin basınç dayanımları ile $3 \times 3 \mathrm{~cm}$ boyutlu numunelerin eğilme dayanımları DiwickRoell Z010 Universal test cihazı ile bulunmuştur.

\subsubsection{Kül Fırınında Yakma İșlemi}

Seçilmiş altı numunenin etüvde kurutulmasının ardından $150,200,250$ ve $300^{\circ} \mathrm{C}$ sicaklığa $10 \mathrm{dk}$ süreyle maruz bırakılmıştır. Numunelerin bu sıcaklıklarda ağırlık değişimleri belirlenmiștir.

\section{BULGULAR VE TARTISMMA}

\subsection{Birim Hacim Ağırlık ve Su Emme Değerleri}

Kompozitlerin birim hacim ağırlık değerleri
Şekil 6'da ve su emme değerleri Şekil 7'de verilmiştir. Perlit katkı oranı arttıkça örneklerin birim hacim ağırlıkları da azalmıştır. Kamış 1zgaralı üretilen örneklerin birim hacim ağırlık değerleri diğer örneklerden daha düşük bulunmuştur. Kamışın çift tabakalı olarak kullanıldığı örneklerin birim hacim ağırlıkları daha küçük bulunmuştur. Bunun nedeni kamış ile hamur arasındaki ara yüzey boşlukları ile açıklanabilir. Ayrıca kamışların içi boş olduğundan daha hafiftirler. Kamış 1zgaralı ve \%10 perlit katkılı örneklerin su emme oranları daha düşük bulunmuştur. Birim hacim ağırlıkları yüksek olan örneklerin su emme oranları daha düşük bulunmuştur. Kontrol örneğinin su emme oranı en büyük bulunmuştur.

Vermikülit katkılı örneklerin çinko boraks katkılı örneklere göre, birim hacim ağırlıkları düşük ve su emme oranları daha yüksek bulunmuştur. Boşluklu ve hafif malzemelerin su emme oranları da daha yüksek bulunmuştur.

Perlit ve vermikülit katkılı örneklerde mineral katkı oranı arttıkça birim hacim ağırlık azalırken su emme oranı artmıştır. Bunun nedeni ise perlit ve vermikülit tanecik yapısının boşluklu olması dolayısıyla kompozit içerisinde açık veya kapalı boşluklar meydana gelmiştir. $\mathrm{Bu}$ sayede boşluk oranı azaldığından hem birim hacim ağırlık değeri artmış hem de aynı nedenle su emme oranı azalmıştır.

\subsection{Ultrasonik Ses Geçiş Hızı ve Isı İletim Katsayıları}

Kompozitlerinin Ultrasonik ses geçiş hızı Şekil 8'de verilmiştir.

Birim hacim ağırlığı yüksek olan vermikülit ve çinko boraks katkılı örneklerin ultrasonik ses geçirgenlik değerleri daha yüksek bulunmuştur. Yani ses bu örneklerden geçerken sönümlenememiştir. Çünkü bu örneklerde boşluk oranı çok azdır. Oysa boşluklu bir yapıya sahip olan perlit katkılı örneklerin ultrasonik ses geçiş hızları daha düşük bulunmuştur. $\mathrm{Bu}$ örnekler boşlukları sayesinde geçen ses dalgalarını 


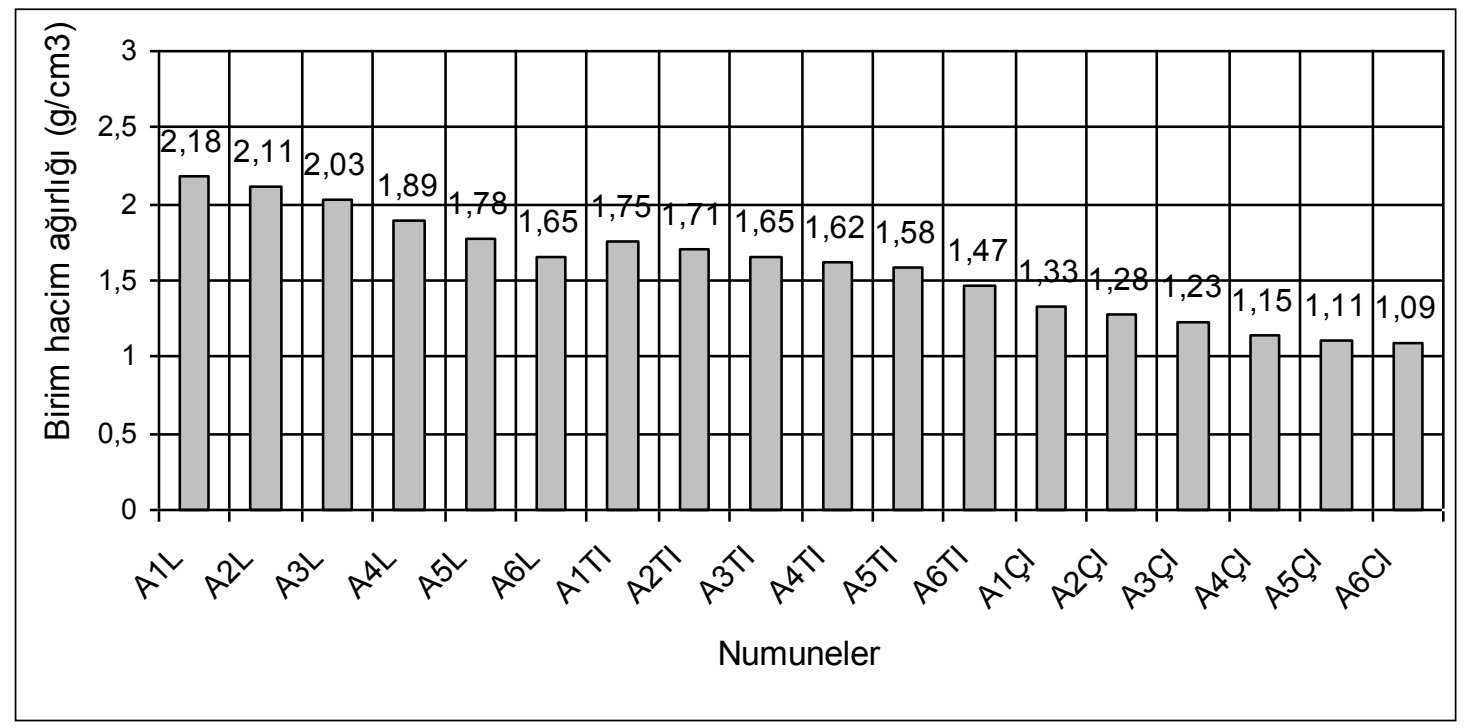

Şekil 6. Kompozitlerin birim hacim ağırlık değerleri

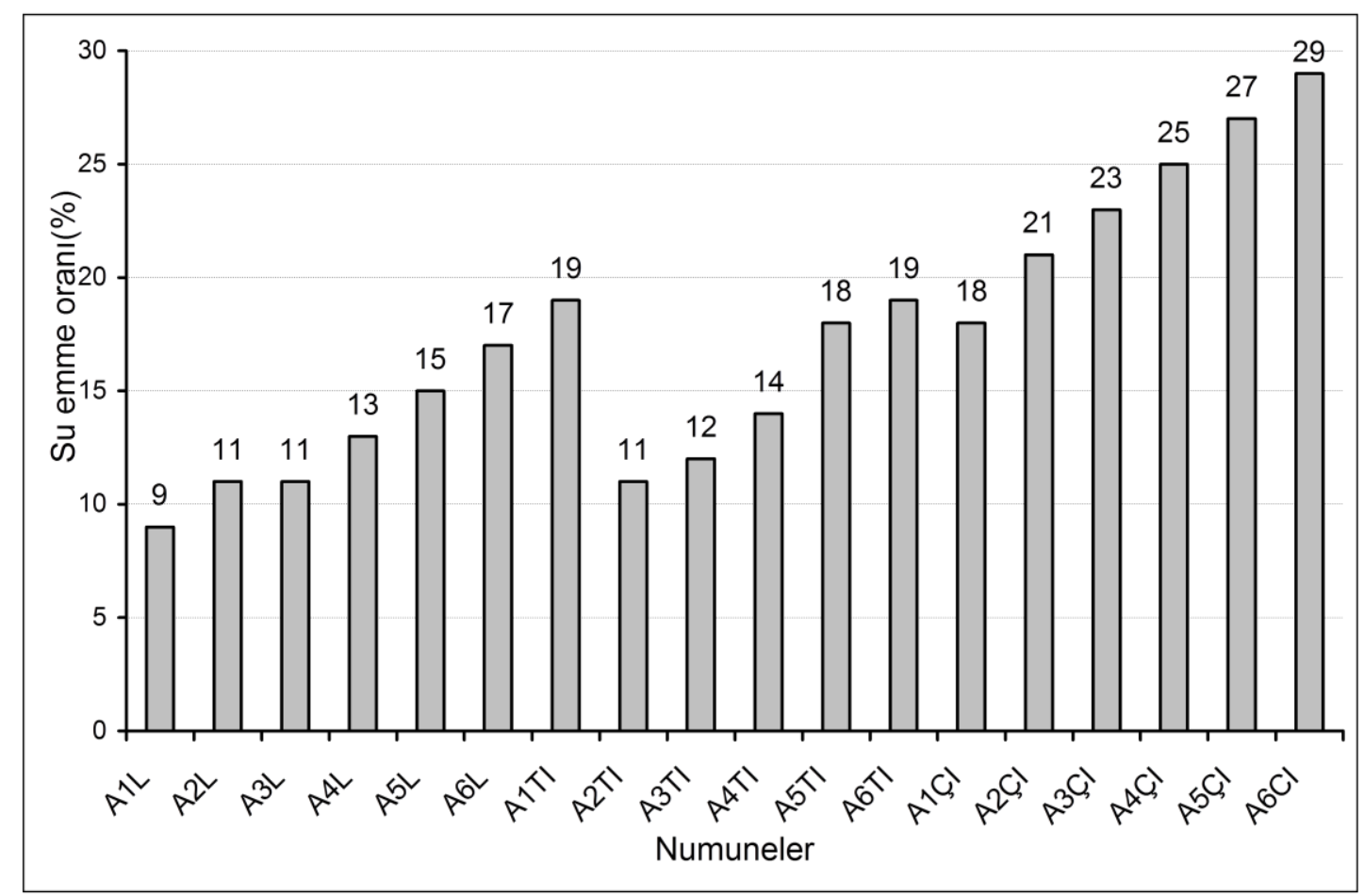

Şekil 7. Kompozitlerin su emme değerleri 


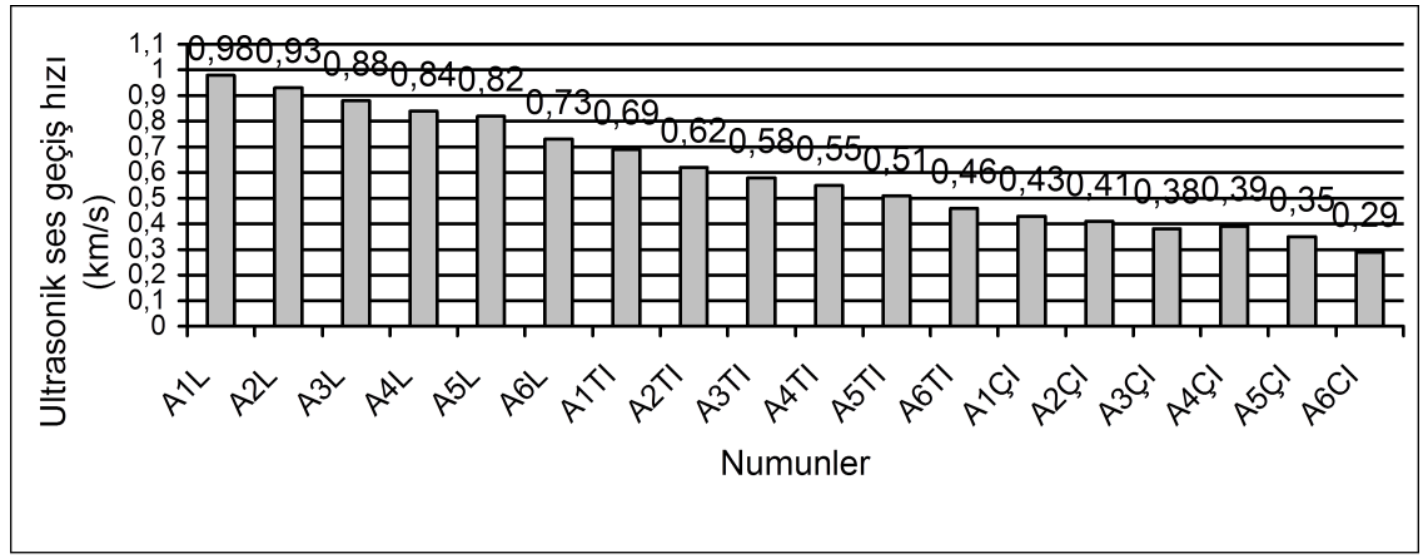

Şekil 8. Kompozitlerinin ultrasonik ses geçiş hızları

sönümlemiştir. Örneklerin 1sı iletim katsayısı ile ultrasonik ses geçiş hızları arasında direk ilişkiler mevcuttur. Yani birisi artarken diğeri de artmaktadır. Zira bu iki özellik te boşluk yapısı ile direk ilintilidir.

Çift sıra halinde kamış kullanılarak ızgaralı üretilen örneklerin ultrasonik ses geçiş hızları tek sıra halinde kamış kullanılarak 1zgaralı üretilen örneklerden daha düşük bulunmuştur. Bunun anlamı ses malzeme içerisinde sönümlenmiştir. Bunun neden ise kamışın boşluklu olmasıdır. Aynı şekilde bu grup örneklerin 1sı iletim katsayıları da daha düşük bulunmuştur.

\subsection{Isı İletim Katsayıları}

Kompozitlerin 1sı iletim katsayıları Şekil 9'da verilmiştir.

Türk ve uluslararası standartlara göre bir malzemenin 1S1 yalıtım malzemesi olarak tanımlanması için onun sahip olduğu 1sı iletkenlik katsayısının ( $\lambda$ ) $0,1 \mathrm{~W} / \mathrm{mK}$ 'den küçük olması gerekir. Yukarıdaki tablo incelendiğinde \%10 perlit ve alçı katkılı, A1L, A2L, vemikülit ve alçı katkılı A5L ve A6L adlı örnekler yalıtım malzemesi kabul edilebilir. $\mathrm{Bu}$ örneklerin mikro yapılarının birbiriyle ilişkili veya ilişkisiz birçok boşluk içermesi ile açıklanabilir. Zira söz konusu örneklerin ultrasonik ses geçiş hızları da bunu doğrulamaktadır. Çünkü bu örneklerin ultrasonik ses geçiş hızları daha küçük bulunmuştur. Bunun nedeni yine perlitin boşluklu yapısı ile açıklanabilir. $\mathrm{Bu}$ durum ise söz konusu ses dalgalarının yüzeyden geçerken absorbe edilmesinin bir sonucudur. Oysa çinko boraks katkılı örneklerin hem ultrasonik ses geçiş hızları daha büyük hem de 1sı iletim katsayıları daha büyük bulunmuştur. Burada ilginç bir sonuç ise tek ve çift sıra kamış 1zgaralı örneklerin hem ultrasonik ses geçiş hızları hem de 1sı iletim katsayıları daha düşük bulunmuştur. $\mathrm{Bu}$ durum ise kamışın boşluklu yapısı ile açıklanabilir. Ayrıca perlit tanelerin yı ̆̆ı halinde bulunması alçı ile birbirine güçlü bir şekilde bağlanmaları durumunda bünyelerinde ve kâğıt hamuru arasında oluşturdukları hava boşlukları sayesinde 1sı iletim katsayıları daha düşük bulunmuştur. Genellikle örneklerin birim hacim ağırlığı arttıkça malzemenin isı iletim katsayısının değeri de düşmektedir.

\subsection{Basınç ve Eğilme Dayanımı}

Kompozitlerinin basınç dayanımları Şekil 10'da ve eğilme dayanımları Şekil 11 'de verilmiştir.

Perlit katkı oranı arttıkça basınç dayanımı düşmüştür. $\mathrm{Bu}$ durum kompozitin ana fazını oluşturan atık kâğıt hamurunun yapısı ve mineral 


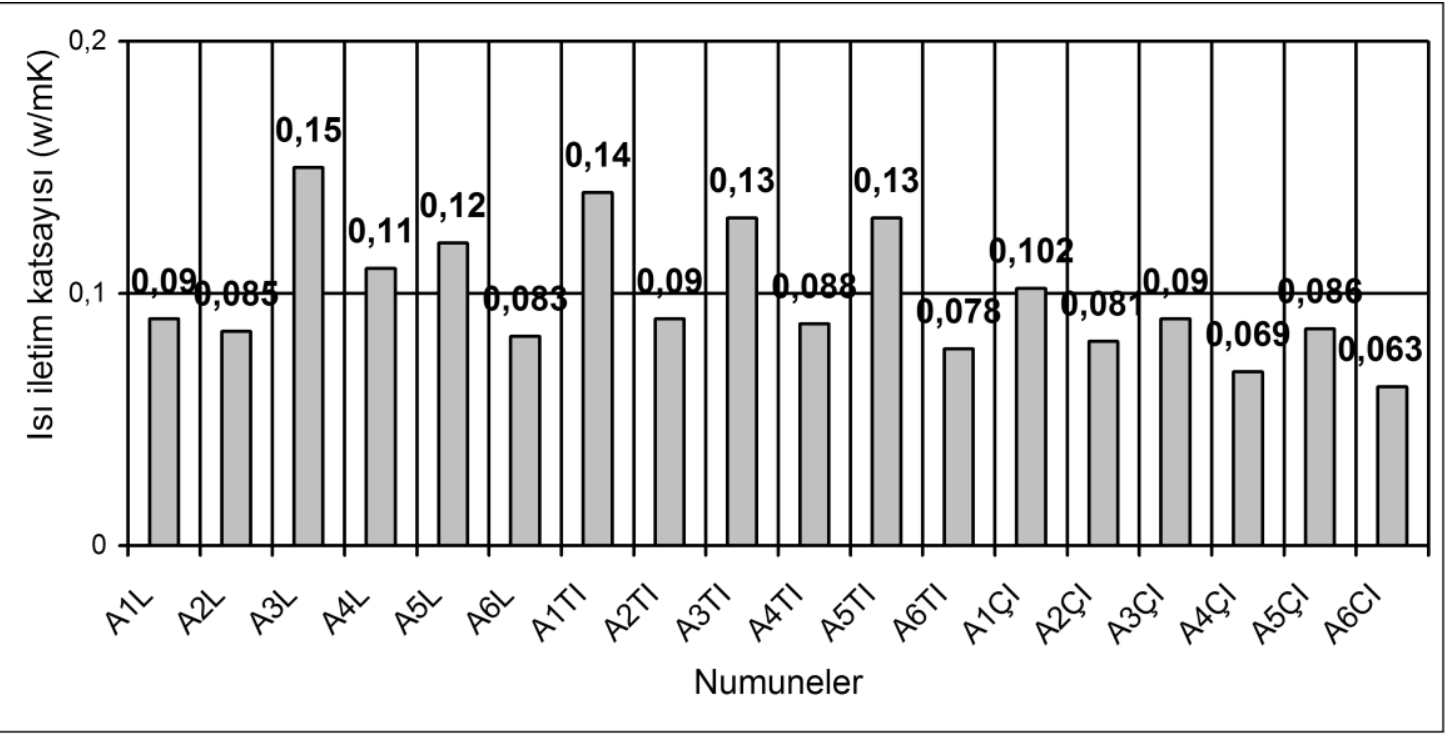

Şekil 9. Kompozitlerinin 1sı iletim katsayıları

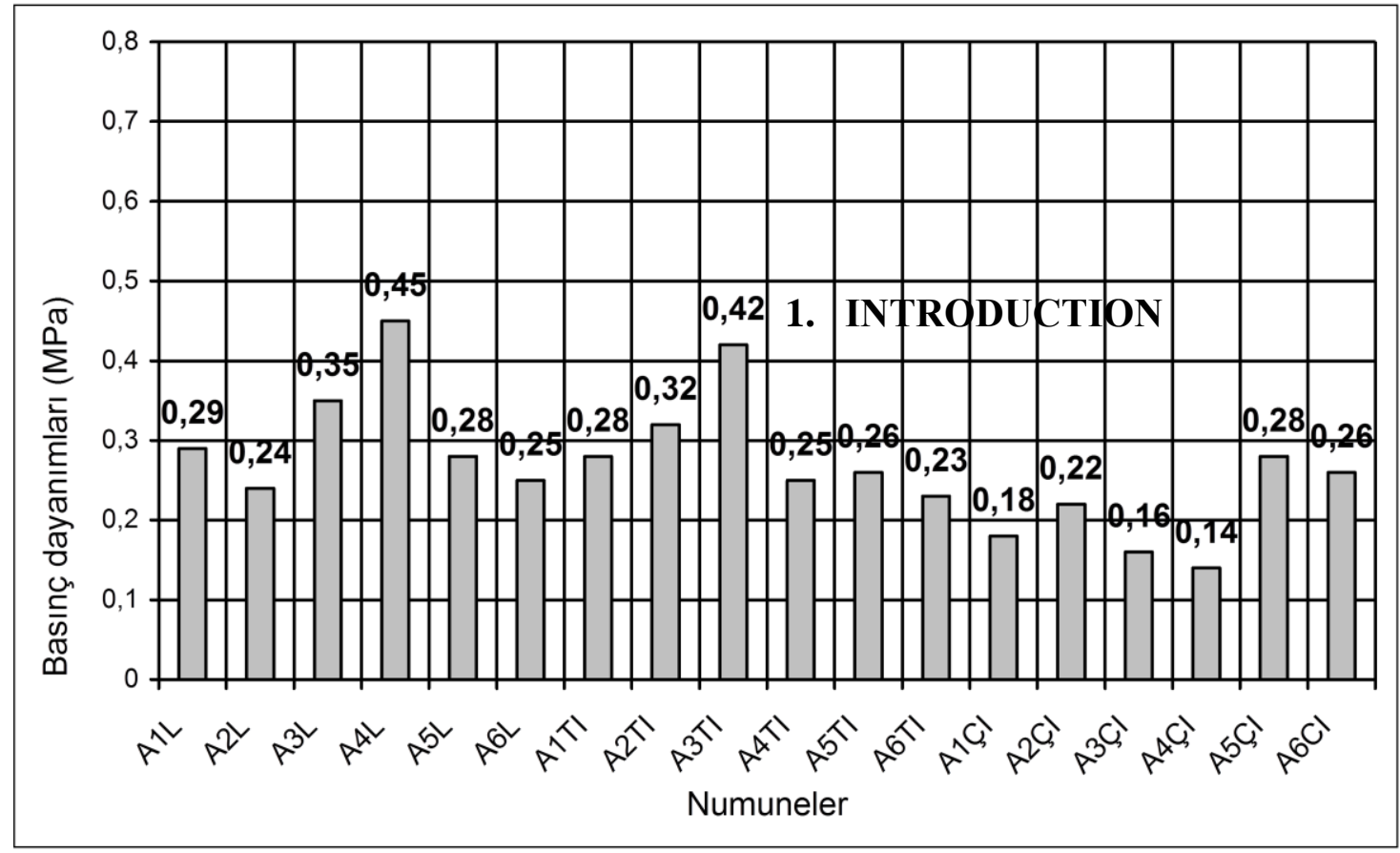

Şekil 10. Kompozitlerinin basınç dayanımları 


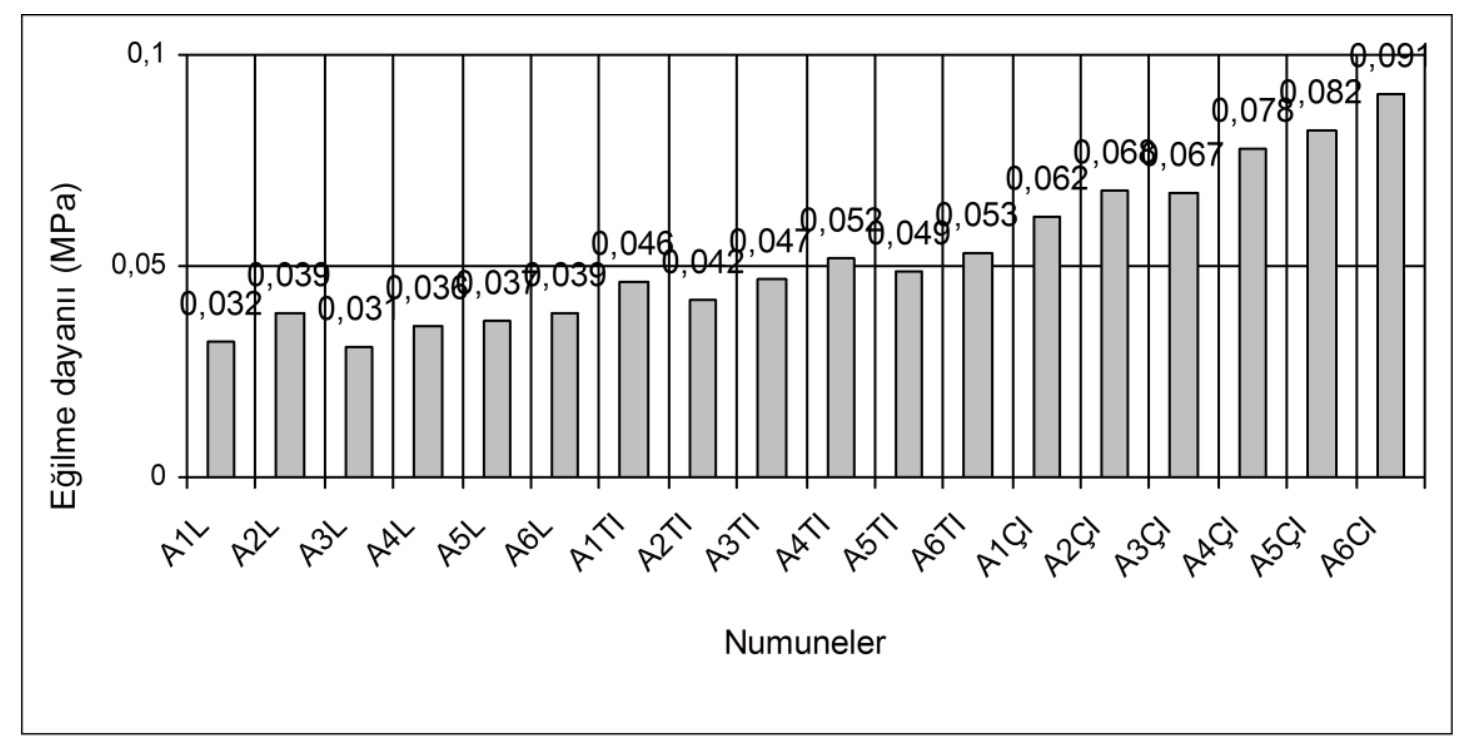

Şekil 11. Kompozitlerinin eğilme dayanımları

katkıların numunelere sertlik kazandırması ile açıklanabilir. Genellikle 1zgaralı örneklerin basınç dayanımları azalırken eğilme dayanımları daha yüksek bulunmuştur. $\mathrm{Bu}$ durum kamışların kompozit içerisinde lifli donatı olarak yer alması ile açıklanmıştır. Diğer yandan vemikülit ve perlitli örneklerin basınç ve eğilme dayanımları çinko boraks katkılı örneklerden daha yüksek bulunmuştur. Aslında birim hacim ağırlığ 1 ile 1s1 iletim katsayısı düşük olan örneklerin basınç dayanımlarının düşük olması beklenen bir durumdur. Diğer yandan perlit katkılı örneklerin eğilme dayanımları vermikülit katkılı örneklerden daha yüksek bulunmuştur. $\mathrm{Bu}$ sonuçlar perlit ve vermikülitin kompozit içerisinde sertlik veya esneklik kazandırması ile açıklanabilir. Bulunan değerler yalıtım malzemesi için yeterli düzeydedir.

\subsection{Yangın Direnci}

Numunelerin kütle kayıpları Şekil 12'de verilmiştir.

Kompozitlerin yanma etkisiyle kütle kayılarına göre, firın sıcaklığı arttıkça kütle kaybı da artmaktadır. Tüm örneklerde katkı oranı arttıkça kütle kaybı azalmaktadır. Genel olarak vermikülit katk1lı örneklerin tüm sicaklıklarda elde edilen kütle kayıpları daha düşük bulunmuştur. En düşük kütle kayıpları $\% 20$ perlit ve $\% 5$ vermikülit katkılı örneklerde elde edilmiştir.

Tek ve çift sıra 1zgaralı üretilen kompozitlerin yanma etkisiyle kütle kayıplarına göre, firın sıcaklığı arttıkça kütle kaybı da artmaktadır. Genel olarak çinko boraks katkılı örneklerin tüm sıcaklıklarda elde edilen kütle kayıpları daha düșük bulunmuştur. $75,100,125$ ve $150^{\circ} \mathrm{C}$ sicaklıklarda vermikülit katkılı örneklerin kütle kayıpları, çinko boraks katkılı örneklerinin kütle kayıplarından sirayla \%15, 22, 28 ve $\% 33$ daha düşük bulunmuştur. Bunun nedeni vermikülitin kimyasal ve içyapısı ile açıklanabilir.

\section{SONUÇLAR}

Çalışmadan aşağıdaki sonuçlar çıkarılmıştır:

1. Perlit katkılı örneklerin birim hacim ağırlıkları daha düşük ancak su emme oranları diğerlerine göre daha yüksek bulunmuştur. $\mathrm{Bu}$ grup 
örneklerin ultrasonik ses geçiş hızları diğerlerine göre daha düşük bulunmuştur.

2. Çalışmada perlit katkılı numunelerin ultra ses geçiş hızı ve 1sı iletim katsayısı daha düşük bulunmuştur.

3. Bütün örneklerin eğilme ve basınç dayanımları standartların öngördüğü değerlerin üzerinde bulunmuştur.

4. Tek ve çift sıra 1zgaralı olarak üretilen örneklerin 1S1 iletkenlik katsayıları oldukça düşük bulunmuştur. $\mathrm{Bu}$ örneklerin eğilme dayanımları da yüksek bulunmuştur.

5. Vemikülit katkılı örneklerin yangın dirençleri daha yüksek bulunmuştur.

$\mathrm{Bu}$ çalışma atık gazete kâğıdı değerlendirilerek bir yalıtım malzemesinin üretilebileceğini göstermiştir. Üretilen bu yalıtım malzemesi hem yerel ve hem de ekonomiktir. İçeriğindeki vermikülit ise bu yalıtım malzemesini yangına karşı daha dirençli bir malzeme yapmaktadır.

\section{KAYNAKLAR}

1. Binici H, Aksoğan O., 2015. Engineering Properties of Insulation Material Made with Cotton Waste and Fly Ash, Journal of Material Cycles and Waste Management, 17- 157-162.

2. Briga-Sa A, Da Teixeira N, Pinto J, Caldeira F, Varum H, Paiva A, 2013. Textile Waste as an Alternative Thermal Insulation Building Material Solution, Construction and Building Materials;38:155-160.

3. Binici H, Kaplan H, Y1lmaz S., 2007. Influence of Marbleand Lime Stone Dusts as Additives on Some Mechanical Properties of Concrete, Scientific Research and Essay; 9: 372-379.

4. Binici H, Yucegok F, Aksogan O, Kaplan H., 2008. Effect of Corncob, Wheat Strawand Plane Leaf Ashes as Mineral Admixtures on Concrete Durability, ASCE, Civil Engineering Materials, 20: 478-483.

5. Binici H, Shah T, Aksogan O, Kaplan H., 2008. Durability of Concrete Made with Granite Andmarble as Recycle Aggregates, Journal of Materials Processing Technology, 208: 299308.
6. Binici H, Arocena J, Kapur S, Aksogan O., Kaplan H., 2009. Microstructure of Red Brick Dust and Ground Basaltic Pumice Blended Cement Mortars Exposed to Magnesium Sulphate Solutions, Canadian Civil Engineering Journal,36: 1784-1793.

7. Binici, H, Gemci R, Aksogan O, Kaplan H., 2010. Insulation Properties of Bricks Made with Cotton and Textile Ash Wastes, International Journal of Materials Research, 101: 894-899.

8. Binici H,Gemci R, Kaplan H., 2012. Physical and Mechanical Properties of Mortar with Out Cement, Construction and Building Materials, 28: 357-361.

9. Binici H, Kapur S, Arocena J, Kaplan H., 2012. The Sulphate Resistance of Cements Containing Red Brick Dust and Ground Basaltic Pumice With Sub-Microscopic Evidence of İntra-Pore Gypsum and Ettringite As Strengtheners, Cement and Concrete Composites,34: 279-287.

10. Binici H,Gemci R, Küçükönder A., 2012. Investigating the Sound Insulation, Thermal Conductivity and Radioactivity of Chipboards Produced with Cotton Waste, Fly Ash and Barite, Construction and Building Materials, 30: 826-832.

11. Binici H, Eken M, Dolaz M, Aksogan O, Kara M., 2014. An Environmentally Friendly Termal Insulation Material from Sunflowerstalk, Textile Waste and Stubble Fibres, Construction and Building Materials, 51: 24-33.

12. Directive 2010/31/EU of the European Parliamentand of the Council on the Energy Performance of Buildings, Official Journal of the European Union, 2010;19:153-162.

13. de Wilde P, Voorden M. 2004. Providing computational support for the election of energy saving building components. Energy Building,36:749-58.

14. Binici H, Gemci R, Kucukonder A., 2012. Investigating the Sound Insulation, Thermal Conductivity and Radioactivity of Chipboards Produced with Cotton Waste, Fly Ash and Barite, Construction and Building Materials, 30: $826-832$. 
15. Karıncaoğlu M., 2010. Kağıt ve Karton Üretimi, I. Cilt-Üretim Hatt1, Cilt-1, 12.

16. Yakut A., Geri Dönüştürülebilir Kullanılmış Kağıttan Yeni Kağıt Üretiminin İrdelenmesi, 8 Tesisat Mühendisliği 2012; 127: 69-75.

17. Eltepe E., 2004. Çinko Borat Üretim Prosesi, Yüksek Lisan Tezi, İzmir Yüksek Teknoloji Enstitüsü, İzmir,.

18. Ayar B., 2007. Çinko Borat Sentezi ve Yüksek Sicaklıklarda Pigment Olarak Kullanılabilmesi, Gazi Üniversitesi Fen Bilimleri Enstitüsü, Şubat

19. ASTM C 67-03 2003. Standard Test Methods for Sampling and Testing Brick and Structural Claytile. Philadelphia, PA: American Society for Testing and Materials.

20. ASTM C 597 1994. Standart Test Method for Pulse Velocity Through Concrete, Annual Book of ASTM Standard.

21. ASTM C 1113-90 1990. Test Method for Thermal Conductivity of Refractories by Hot Wire. 
